\title{
TOWARDS A BETTER COMPREHENSION OF ACUTE MESENTERIC ISCHEMIA AFTER CARDIAC SURGERY. AN ANALYSIS OF 33 PATIENTS.
}

\author{
Raoul Borioni ${ }^{1}$, alessandro bellisario ${ }^{2}$, Luca Weltert $^{2}$, Franco Turani ${ }^{1}$, Mariano Garofalo ${ }^{1}$, \\ Salvatore D'aleo ${ }^{2}$, and Ruggero De Paulis ${ }^{2}$ \\ ${ }^{1}$ Aurelia Hospital \\ ${ }^{2}$ Department of Cardiac Surgery, European Hospital
}

January 29, 2021

\begin{abstract}
Background. Acute mesenteric ischemia (AMI) after cardiac surgery is a rare but serious complication associated to high mortality. The time of onset is the key point to correctly evaluate the clinical scenarios. Methods. Data from adult patients who underwent laparotomy for AMI after elective or urgent cardiac surgery were reviewed (January 2005 - December 2019) to report their anatomoclinical features in relationship to time of onset. Early events (within 48 hours) were allocated to Group 1, whereas late onsets were allocated to Group 2. Results. The incidence of risk factors for non occlusive mesenteric ischemia was higher in Group 1 (chronic renal failure $80 \%$ vs $38.8 \%, \mathrm{P}<0.05$, use of inotropes $60 \%$ vs $5.5 \%, \mathrm{P}<0.01$, early oligo-anuria requiring CRRT $80 \%$ vs $16.6 \%, \mathrm{P}<0.01$, prolonged ventilation $46.6 \%$ vs $5.5 \%, \mathrm{P}<0.05$ ), where a significative occurrence of postoperative de novo atrial fibrillation was noted in Group $2(55 \%$ vs $5.5 \%, \mathrm{P}<0.01)$. The number of patients who required bowel resection was proportionally higher in the Group 2 Conclusions. Two well distincted categories of AMI after cardiac surgery can be classified. The first consists of patients with well-known risk factors developing ischemia as a result of severe visceral hypoperfusion The second consists of patients with low comorbidity who experience late AMI as a consequence of "trigger events", mainly de novo atrial fibrillation. This classification may be useful to better alert the medical staff to the possibility of bowel ischemia at any time after cardiac surgery, promoting early diagnosis and treatment.
\end{abstract}

\section{Hosted file}

AMI Combined Borioni rev Weltert18-2-2021.pdf available at https://authorea.com/users/ 392638/articles/506414-towards-a-better-comprehension-of-acute-mesenteric-ischemiaafter-cardiac-surgery-an-analysis-of-33-patients 